E. Mannucci $\cdot$ L. Pala $\cdot$ S. Ciani $\cdot$ G. Bardini $\cdot$

A. Pezzatini - I. Sposato - F. Cremasco - A. Ognibene •

C. M. Rotella

\title{
Hyperglycaemia increases dipeptidyl peptidase IV activity in diabetes mellitus
}

Received: 25 August 2004 / Accepted: 5 January 2005 / Published online: 29 April 2005

(C) Springer-Verlag 2005

\begin{abstract}
Aims/hypotheses: Chronic hyperglycaemia increases dipeptidyl peptidase IV (DPP-IV) activity in endothelial cells in vitro. The present study was designed to assess the effect of high glucose on circulating DPP-IV activity in patients with type 1 and type 2 diabetes. Methods: Plasma DPP-IV activity was measured in 29 patients with type 1 diabetes and 29 age-, sex- and BMI-matched control subjects. We also assessed DPP-IV activity in 31 type 2 diabetic patients with $\mathrm{HbA}_{1} \mathrm{c}>8.5 \%$ and in plasma from matched groups of 31 newly diagnosed diabetic subjects with $\mathrm{HbA}_{1} \mathrm{c}$ $<7.5 \%, 31$ subjects with IGT and 62 subjects with NGT. In a further sample of 66 type 2 diabetic patients, a longitudinal study was also performed to evaluate variations in DPP-IV activity and $\mathrm{HbA}_{1} \mathrm{c}$ over 3 months. Results: DPP-IV activity in type 1 diabetic patients was not significantly different from that in control subjects; however, a significant correlation between DPP-IV and $\mathrm{HbA}_{1} \mathrm{c}$ was observed in diabetic subjects $(r=0.47 ; p<0.01)$. Type 2 diabetic patients with $\mathrm{HbA}_{1} \mathrm{c}>8.5 \%$ showed significantly $(p<0.05)$ higher DPP-IV activity (mean \pm SD $27.7 \pm 7.1$ U/l) than newly diagnosed diabetic patients and subjects with IGT (22.1 \pm 6.0 and $18.8 \pm 8.8 \mathrm{U} / 1$, respectively). Variations in DPP-IV activity over 3 months in type 2 diabetic patients showed
\end{abstract}

E. Mannucci

Diabetology, Geriatric Unit,

Department of Critical Care, University of Florence,

Florence, Italy

L. Pala $\cdot$ S. Ciani $\cdot$ G. Bardini $\cdot$ A. Pezzatini $\cdot$ F. Cremasco $\cdot$

C. M. Rotella $(\triangle)$

Section of Endocrinology,

Department of Clinical Pathophysiology,

University of Florence,

Viale Pieraccini 6,

50139 Firenze, Italy

e-mail: c.rotella@dfc.unifi.it

Tel.: +39-05-4271427

Fax: +39-05-4271474

I. Sposato $\cdot$ A. Ognibene

Central Laboratory,

Careggi General Hospital,

Florence, Italy a significant positive correlation with variations in $\mathrm{HbA}_{1} \mathrm{c}$ $(r=0.26 ; p<0.05)$. Conclusions/interpretation: Chronic hyperglycaemia induces a significant increase in DPP-IV activity in type 1 and type 2 diabetes. This phenomenon could contribute to the reduction in circulating active glucagon-like peptide-1 and to the consequent postprandial hyperglycaemia in type 2 diabetic patients with poor metabolic control.

Keywords Diabetes mellitus - Dipeptidyl peptidase IV

Abbreviations DPP: dipeptidyl peptidase - GIP: gastric inhibitory polypeptide - GLP-1: glucagon-like peptide 1

\section{Introduction}

Glucagon-like peptide 1 (GLP-1) is a gastrointestinal hormone, mainly secreted after meals, which enhances glucose-induced insulin secretion $[1,2]$ and induces satiety [3]. It has been reported that GLP-1 levels after a mixed meal $[4,5]$ and after an oral glucose load $[6,7]$ are reduced in patients with type 2 diabetes. Reduction in oral glucosestimulated active GLP-1 levels in patients with type 2 diabetes has also been observed in isoglycaemic and isoinsulinaemic conditions, i.e. during a euglycaemic-hyperinsulinaemic clamp [7]. This means that, although blood glucose and insulin levels immediately after the meal could affect GLP-1 secretion [8], differences in these parameters cannot explain the impairment of peptide response to oral glucose observed in diabetic patients. However, the reduction in postprandial circulating active GLP-1 in type 2 diabetic subjects could be the consequence of chronic hyperglycaemia. The impairment of the GLP-1 response to meals could contribute to the reduction in early postprandial insulin secretion in patients with type 2 diabetes; in fact, the administration of GLP-1 receptor antagonists to healthy volunteers elicits an impairment of meal-induced insulin secretion and an increase in postprandial glycaemia similar to that observed in type 2 diabetes $[9,10]$. 
GLP-1 is rapidly inactivated in vivo, with the cleavage of an N-terminal dipeptide; inactivation is catalysed by dipeptidyl peptidase IV (DPP-IV), an enzyme which is produced by endothelial cells in different parts of the body and circulates in plasma [11]. It is still not clear whether the reduction in meal- or oral glucose-stimulated GLP-1 levels in type 2 diabetic patients is due to impairment of secretion, an increase in degradation, or both. GLP-1 gene expression and peptide synthesis have been reported to be unmodified with respect to controls in rodent models of type 1 and type 2 diabetes [12], whereas no data on the effects of high glucose on DPP-IV expression and activity are available in animal models. GLP-1 kinetics were reported to be unmodified with respect to control subjects in a small sample of type 2 diabetic patients [13], suggesting that the reduction in active GLP-1 in diabetic patients could be attributable to impairment of secretion rather than increased degradation. In fact, circulating DPP-IV levels were reported to be reduced in a small sample of elderly patients with type 2 diabetes [14]; in a study on another small sample of subjects, no significant difference in circulating enzyme activity was detected between type 2 diabetic patients and matched healthy controls [5]. On the other hand, DPP-IV mRNA expression and enzyme activity have been reported to be stimulated by hyperglycaemia in human endothelial cells in vitro [15]. In order to elucidate the relationships between chronic hyperglycaemia and DDP-IV in diabetes, enzyme activity was studied in blood samples from patients with type 1 and type 2 diabetes, compared with subjects with IGT or NGT. A longitudinal study of DPP-IV activity over 3 months was also performed in type 2 diabetic patients, in order to explore the possible correlation between variations in enzyme activity and metabolic control.

\section{Subjects, materials and methods}

DPP-IV activity in patients with type 1 diabetes Serum DPP-IV activity was measured in a consecutive series of 29 outpatients (16 women, 13 men) with type 1 diabetes, aged $34.3 \pm 6.1$ years, with a duration of diabetes of $15.4 \pm$ 9.9 years, a BMI of $23.2 \pm 2.7 \mathrm{~kg} / \mathrm{m}^{2}, \mathrm{HbA}_{1} \mathrm{c}$ of $7.5 \pm 1.3 \%$ and serum C-peptide $<0.1 \mathrm{ng} / \mathrm{ml}$. For comparison, a sex-, age- and BMI-matched sample of 29 healthy volunteers was also studied. Subjects in the control group had an age of $35.7 \pm 8.2$ years and a BMI of $23.3 \pm 2.9 \mathrm{~kg} / \mathrm{m}^{2}$.

DPP-IV activity in patients with type 2 diabetes: crosssectional study Serum DPP-IV activity was measured in a consecutive series of 31 outpatients ( 20 women, $11 \mathrm{men}$ ), aged $67.4 \pm 9.1$ years, with type 2 diabetes of at least 1 -year duration and $\mathrm{HbA}_{1} \mathrm{c}>8.5 \%$. Of the individuals enrolled, seven were treated with insulin, two with metformin, nine with combinations of two or more hypoglycaemic agents, and 12 with combinations of insulin and hypoglycaemic agents; one patient was not receiving any hypoglycaemic treatment. Their mean $( \pm \mathrm{SD})$ BMI was $28.9 \pm 5.5 \mathrm{~kg} / \mathrm{m}^{2}$. These patients were compared with age-, sex- and BMI- matched subjects selected from individuals enrolled in a study assessing the prevalence of diabetes by oral glucose tolerance testing in a general population sample in a suburban township of Florence [16]. These control subjects consisted of: (1) 31 newly diagnosed type 2 diabetic subjects (fasting glucose $>7 \mathrm{mmol} / \mathrm{l}$ and/or 2 -h postload glucose $>11.1 \mathrm{mmol} / \mathrm{l}$ ), with $\mathrm{HbA}_{1} \mathrm{c}<7.5 \%$, aged $66.7 \pm 8.1$ years and with BMI $28.8 \pm 2.9 \mathrm{~kg} / \mathrm{m}^{2}$, who were not receiving any hypoglycaemic treatment; (2) 31 subjects with IGT (2-h postload glucose $>7.7 \mathrm{mmol} / \mathrm{l}$, with fasting glucose $\leq 7 \mathrm{mmol} / \mathrm{l}$ ), aged $65.9 \pm 7.8$ years and with BMI $28.7 \pm$ $2.7 \mathrm{~kg} / \mathrm{m}^{2}$; and (3) 62 subjects with NGT and normal fasting glycaemia, aged $66.3 \pm 6.1$ years and with BMI $28.7 \pm$ $2.8 \mathrm{~kg} / \mathrm{m}^{2}$.

For each of the diabetic outpatients enrolled, the first subject in the study database for each category listed (the first two for the NGT group) of the same sex, age ( \pm 2 years) and BMI $\left( \pm 1 \mathrm{~kg} / \mathrm{m}^{2}\right)$ was enrolled.

DPP-IV activity in patients with type 2 diabetes: longitudinal study Variations in circulating DPP-IV activity over a period of $90 \pm 15$ days were assessed in a further sample of 66 type 2 diabetic outpatients (36 women, 30 men) with normal liver function tests, aged $61.8 \pm 13.7$ years, with duration of diabetes $11.8 \pm 9.2$ years, BMI $29.0 \pm 5.9 \mathrm{~kg} / \mathrm{m}^{2}$ and $\mathrm{HbA}_{1} \mathrm{c} 7.6 \pm 1.3 \%$. Among these patients, those who underwent any variation in dose or type of hypoglycaemic drug prescribed during the 3-month follow-up were excluded from the study, so that all the patients enrolled maintained the same pharmacological treatment for the duration of observation.

Informed consent All the subjects enrolled provided their informed consent. The investigation was carried out in accordance with the Declaration of Helsinki, as revised in 2000 .

Laboratory determinations Blood samples were drawn in the morning, after overnight fasting. In diabetic patients, $\mathrm{HbA}_{1} \mathrm{c}$ was determined using an HPLC method (Menarini Diagnostics, Florence, Italy), with an upper limit of reference range for healthy subjects of $5.8 \%$.

DPP-IV activity was measured with a colorimetric assay. Gly-Pro-4 p-nitroanilide, a chromogenic substrate of DPP-IV, is hydrolysed into the dipeptide Gly-Pro and the product 4-nitroaniline, the rate of appearance of which can be measured spectrophotometrically $[17,18]$. To evaluate within- and between-run precision of the DPP-IV assay, the activities of serum samples with low (15 U/l), middle $(30 \mathrm{U} / 1)$ and high $(70 \mathrm{U} / \mathrm{l})$ activity were assessed ten times in 5 days. The coefficients of variation were 2.6, 3.4 and $2.3 \%$, respectively for within-run precision and $1.5,4.8$ and $4.7 \%$, respectively for between-run precision [15].

In order to exclude interference of glucose with the assay, DPP-IV (Linco, St Charles, MO, USA) 100 U/1 was incubated at $37^{\circ} \mathrm{C}$ in HEPES buffer without glucose, and with glucose 5.5 or $22 \mathrm{mmol} / \mathrm{l}$, and activity was measured after $4 \mathrm{~h}, 24 \mathrm{~h}$ and 7 days. Measured activity with glucose 5.5 and $22 \mathrm{mmol} / \mathrm{l}$, when compared with that without 
glucose, was $103 \pm 3$ and $101 \pm 3 \%$, respectively after $4 \mathrm{~h}$, $106 \pm 1$ and $105 \pm 3 \%$ after $24 \mathrm{~h}$ and $104 \pm 4$ and $102 \pm 4 \%$ after 7 days (all not significant, ANOVA).

Statistical analysis Because DPP-IV had a normal distribution, Student's unpaired $t$-test was used for comparisons between pairs of groups, ANOVA with the Bonferroni post hoc test for comparisons among more than two groups, and Pearson's methods for the assessment of correlations. Stepwise multiple linear regression was used for multivariate analysis. Significance was assumed at $p<0.05$.

\section{Results}

Circulating DPP-IV activity in type 1 diabetic patients DPP-IV activity in blood samples from type 1 diabetic patients was not significantly different from that of samples from matched control subjects $(36.2 \pm 11.7$ vs $34.5 \pm$ $11.8 \mathrm{U} / \mathrm{l})$. In diabetic patients, DPP-IV activity showed a significant correlation with $\mathrm{HbA}_{1} \mathrm{c}$ (Fig. 1); in both samples, the correlations of DPP-IV activity with age and BMI were not statistically significant.

Circulating DPP-IV activity in type 2 diabetic patients: cross-sectional study When DPP-IV activity was compared in type 2 diabetic patients with $\mathrm{HbA}_{1} \mathrm{c}>8.5 \%$ and in matched subjects with (1) newly diagnosed diabetes and $\mathrm{HbA}_{1} \mathrm{c}<7.5 \%$, (2) IGT and (3) NGT, the difference among groups was statistically significant ( $p<0.01$ at ANOVA); in post hoc analysis (Bonferroni), DPP-IV activity was significantly higher $(p=0.04)$ in type 2 diabetic patients with $\mathrm{HbA}_{1} \mathrm{c}>8.5 \%$ than in subjects with IGT or NGT. On the other hand, when newly diagnosed patients with mild hyperglycaemia were compared with those with IGT or NGT, no significant difference was observed; similarly, DPP-IV activity in subjects with IGT was not significantly different from that measured in individuals with NGT (Fig. 2). Among type 2 diabetic patients with $\mathrm{HbA}_{1} \mathrm{c}>8.5 \%$, a significant correlation of DPP-IV activity with $\mathrm{HbA}_{1} \mathrm{c}$

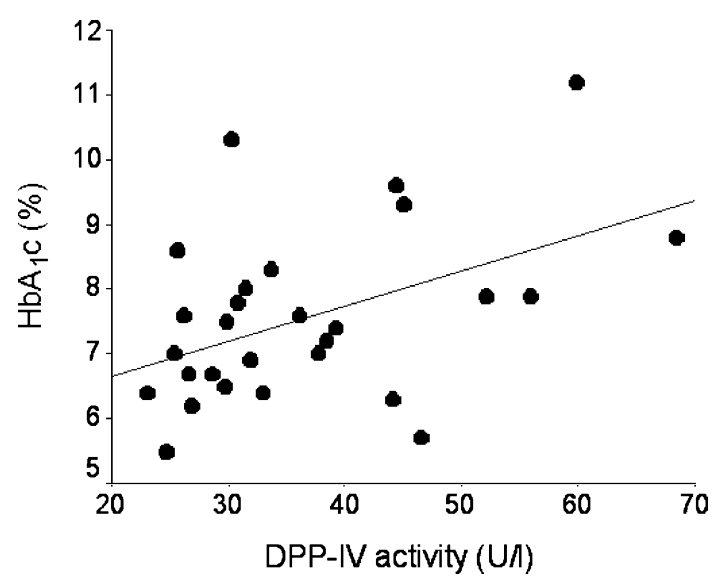

Fig. 1 Correlation between $\mathrm{HbA}_{1} \mathrm{c}$ and plasma dipeptidyl peptidase IV $(D P P-I V)$ activity in patients with type 1 diabetes and without residual insulin secretion $(r=0.47, p<0.01)$

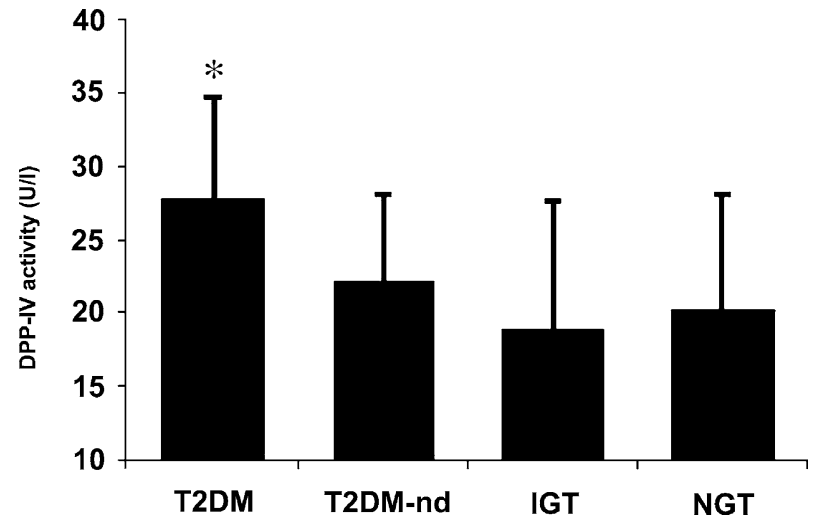

Fig. 2 Plasma dipeptidyl peptidase IV (DPP-IV) activity in matched samples of subjects with: (1) known type 2 diabetes and $\mathrm{HbA}_{1} \mathrm{c}$ $>8.5 \%(T 2 D M ; n=31)$, (2) newly diagnosed type 2 diabetes and $\mathrm{HbA}_{1} \mathrm{c}<7.5 \%(T 2 D M-n d ; n=31),(3) I G T(n=31)$ and (4) $N G T(n=62)$. Data are expressed as means $\pm \mathrm{SD}$. ANOVA, $p<0.01$; Bonferroni test, ${ }^{*} p<0.05$ vs IGT and NGT

$(r=0.42, p<0.01)$, but not age $(r=-0.08)$ or BMI $(r=-0.09)$ was observed.

Circulating DPP-IV activity in type 2 diabetic patients: longitudinal study In a further sample of 66 patients with

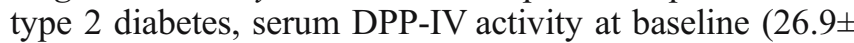
$7.5 \mathrm{U} / 1)$ showed a significant inverse correlation with age $(r=-0.31 ; p=0.02)$ and a significant direct correlation with $\mathrm{HbA}_{1} \mathrm{c}(r=0.25 ; p=0.04)$, but not with BMI. After 3 months, no significant variation in mean $\mathrm{HbA}_{1} \mathrm{c}, \mathrm{BMI}$ or DPP-IV activity in the whole sample was observed (data not shown). Variations in DPP-IV activity in individual patients (Fig. 3) were directly correlated to variations of $\mathrm{HbA}_{1} \mathrm{c}(r=0.26 ; p=0.04)$, but not in BMI $(r=0.20 ; p>0.05)$; the same results were obtained using stepwise multiple linear regression with variation in DPP-IV as the dependent variable and variation in $\mathrm{HbA}_{1} \mathrm{c}$ and of $\mathrm{BMI}$ as putative factors $(\beta=0.46$ and -0.12 respectively; $p=0.03$ for variation in $\mathrm{HbA}_{1} \mathrm{c}$ only).

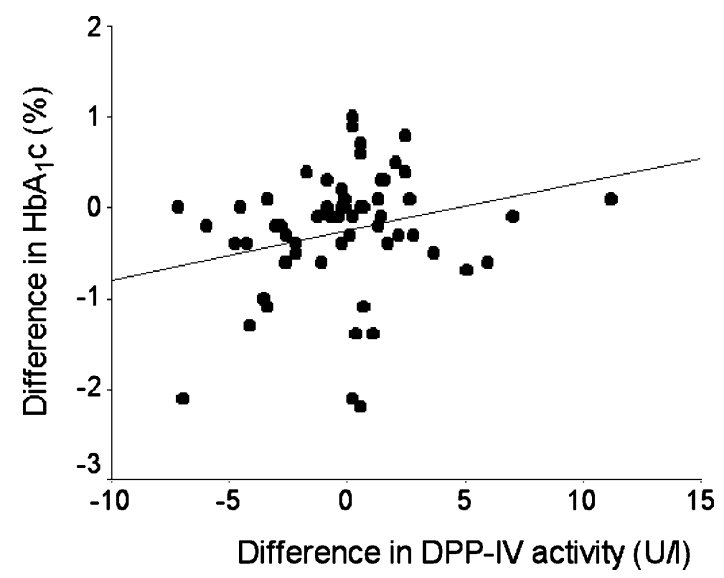

Fig. 3 Correlation between differences from baseline in $\mathrm{HbA}_{1} \mathrm{c}$ and plasma dipeptidyl peptidase IV $(D P P-I V)$ activity in individual type 2 diabetic patients after 3 months of longitudinal observation $(r=0.26$; $p<0.05$ ) 


\section{Discussion}

The present data show for the first time that circulating DPP-IV activity has a direct correlation with the degree of hyperglycaemia in both type 1 and type 2 diabetic patients. Furthermore, longitudinal observation shows that variations in DPP-IV are correlated with variations in $\mathrm{HbA}_{1} \mathrm{c}$, meaning that impairment of metabolic control is associated with increased plasma enzyme activity. In fact, although the elevation of enzyme activity in type 2 diabetic patients with poor metabolic control could be due partly to interference from hypoglycaemic treatment [19], such a mechanism was unable to account for the correlation between variations in DPP-IV and $\mathrm{HbA}_{1} \mathrm{c}$ in the longitudinal study. An increase in DPP-IV activity, leading to reductions in active GLP-1 and gastric inhibitory polypeptide (GIP), which stimulate early postprandial insulin secretion, could theoretically induce an elevation of $\mathrm{HbA}_{1} \mathrm{c}$ in type 2 diabetic patients. On the other hand, the correlation between DPP-IV and $\mathrm{HbA}_{1} \mathrm{c}$ in type 1 diabetic patients without residual insulin secretion cannot be attributed to an effect of enzyme activity on the degree of hyperglycaemia.

Taken together, these data suggest that chronic hyperglycaemia could lead to stimulation of DPP-IV activity. It should be observed that DPP-IV is expressed at the surface of endothelial cells [15] and that circulating enzyme accounts for only a fraction of total DPP-IV activity. Furthermore, differences in structure and function between circulating and endothelial DPP-IV, and the contribution of each component to incretin degradation, are not known in detail. For this reason, circulating DPP-IV cannot be assumed to be an accurate measure of total DPP-IV activity. The present data do not provide any information on the effect of hyperglycaemia on endothelial cell DPP-IV activity. However, our previous study [15] showed that prolonged exposure to high glucose is capable of increasing DPP-IV expression, confirming the stimulatory effect of chronic hyperglycaemia on enzyme activity. Further studies are needed to verify the impact of the hyperglycaemia-induced increase in endothelial and circulating DPP-IV on meal-stimulated active GLP-1 levels in diabetic patients.

On the other hand, type 2 diabetic patients with a mild to moderate degree of hyperglycaemia, as well as subjects with IGT, do not show significantly elevated plasma DPPIV activity; this suggests that only a severe degree of hyperglycaemia is capable of inducing increased DPP-IV expression. The lack of a significant difference in DPP-IV activity between type 1 diabetic patients and matched controls is attributable to the fact that most diabetic subjects studied had good metabolic control, with a modest elevation of $\mathrm{HbA}_{1} \mathrm{c}$. In fact, in vivo studies have shown a relevant stimulation of endothelial cell DPP-IV mRNA expression and activity with exposure to glucose 11$22 \mathrm{mmol} / \mathrm{l}$. The apparently contrasting results of previous studies reporting unmodified [5] or slightly reduced [14] circulating DPP-IV activity in type 2 diabetic patients could be due either to inadequate sample size or to the inclusion in the samples of some patients with mild or moderate hyperglycaemia.

DPP-IV catalyses the inactivation of several hormones and neuropeptides, including GLP-1 and GIP, another insulinotropic gastrointestinal hormone stimulated by meals. GLP-1 kinetics was reported to be unmodified with respect to control subjects in a sample of type 2 diabetic patients [13], apparently contradicting the present results. However, it should be observed that the small size of the samples or the inclusion of some patients with mild or moderate hyperglycaemia could have prevented the detection of differences. On the other hand, some studies reported a reduction in meal-stimulated circulating levels of intact GIP [5, 8]; furthermore, GIP clearance has been shown to be increased in patients with type 2 diabetes [20], which is consistent with increased DPP-IV activity.

GLP-1 levels after a mixed meal $[4,5]$ and after an oral glucose load $[6,7]$ have been reported to be reduced in patients with type 2 diabetes when compared with matched control subjects. Some of these studies were performed on samples of patients with a mild degree of hyperglycaemia [7], showing that the impairment of the GLP-1 response to meals is an early event in the natural history of diabetes. On the other hand, in the present study the increase in DPP-IV activity was observed only for a higher degree of hyperglycaemia or for chronic hyperglycaemia. The possibility that mild hyperglycaemia is capable of stimulating endothelial cell, but not circulating, DPP-IV activity, cannot be ruled out; however, the hypothesis of an impairment of GLP-1 secretion as an early event leading to glucose intolerance in type 2 diabetic patients appears more probable. This latter hypothesis should be tested in specifically designed studies assessing GLP-1 secretion in vivo in humans.

The mechanisms underlying the increase in circulating DPP-IV activity determined by hyperglycaemia are still unclear. Exposure to high glucose could determine an increase in endothelial DPP-IV mRNA expression and protein secretion, as suggested by previous studies in vitro [15]; alternatively, endothelial damage determined by hyperglycaemia could induce the release of vascular DPP-IV. Finally, hyperosmolarity and/or non-enzymatic glycation could modify circulating enzyme activity.

A limitation of our study arises from the fact that other peptidases, such as fibroblast activation protein $\alpha$, DPP-7, DPP-8, DPP-9 and prolylcarboxypeptidase, could have interfered with the assay. However, these enzymes are present in plasma at much lower concentrations than DPPIV [21]; furthermore, GLP-1 is a substrate for most of those peptidases as well as for DPP-IV.

In conclusion, mild hyperglycaemia does not appear to modify circulating DPP-IV activity, suggesting that the impairment of the GLP-1 response to meals in the earlier phases of type 2 diabetes could be due to a reduction in hormone secretion. However, once moderate or severe hyperglycaemia is established, high glucose induces an increase in DPP-IV activity, which could contribute to the reduction in active GLP-1 levels, and could therefore play a role in the pathogenesis of postprandial hyperglycaemia. 
Furthermore, the increase in DPP-IV activity could determine an increase in circulating levels of the inactivated form of the hormone GLP-1(9-36)amide, which is a GLP1 receptor antagonist $[22,23]$, possibly contributing to hyperglycaemia. The nature of the impaired GLP-1 response in type 2 diabetic patients with mild hyperglycaemia, as well as the relative contribution of the hyperglycaemiainduced elevation of DPP-IV to the reduction in active hormone levels in patients with poor metabolic control, needs further investigation.

Acknowledgements This study was supported by grants from the Ministry of Scientific Research (MIUR 40\% funds), and by unrestricted grants from Menarini Diagnostics Italy, Merck-Sharpe \& Dohme, and Bayer Pharmaceuticals. We wish to thank Drs Laura Raimondi and Rosanna Matucci (Department of Pharmacology, University of Florence, Italy) for their scientific collaboration.

\section{References}

1. Kreymann B, Williams G, Ghatei MA, Bloom SR (1987) Glucagon-like peptide-1 7-36: a physiological incretin in man. Lancet 2:1300-1304

2. D’Alessio DA, Kahn SE, Leusner CR, Ensinck JW (1994) Glucagon-like peptide-1 enhances glucose tolerance both by stimulation of insulin release and by increasing insulin-independent glucose disposal. J Clin Invest 95:2263-2266

3. Gutzwiller JP, Goke B, Drewe J et al (1999) Glucagon-like peptide-1: a potent regulator of food intake in humans. Gut 44:81-86

4. Lugari R, Dell'Anna C, Ugolotti D et al (2000) Effect of nutrient ingestion on glucagon-like peptide-1 (7-36 amide) secretion in human type 1 and type 2 diabetes. Horm Metab Res 32:424-428

5. Vilsboll T, Krarup T, Deacon CF, Madsbad S, Holst JJ (2001) Reduced postprandial concentration of intact biologically active glucagon-like peptide- 1 in type 2 diabetic patients. Diabetes 50:609-613

6. Vaag AA, Holst JJ, Volund A, Beck-Nielsen HB (1996) Gut incretin hormones in identical twins discordant for non-insulindependent diabetes mellitus (NIDDM) — evidence for decreased glucagon-like peptide-1 secretion during oral glucose ingestion in NIDDM twins. Eur J Endocrinol 135:425-432

7. Mannucci E, Ognibene A, Cremasco F et al (2000) Glucagonlike peptide-1 (GLP-1) and leptin concentrations in obese patients with type 2 diabetes mellitus. Diabet Med 17:713-719

8. Toft-Nielsen MB, Damholt MB, Madsbad S et al (2001) Determinants of the impaired secretion of glucagon-like peptide- 1 in type 2 diabetic patients. J Clin Endocrinol Metab 86:37173723

9. Schirra J, Sturm K, Leicht P, Arnold R, Goke B, Katschinski M (1998) Exendin (9-39) is an antagonist of glucagon-like peptide-1 (7-36) amide in humans. J Clin Invest 101:1421-1430
10. Edwards CM, Todd JF, Mahmoudi M et al (1999) Glucagonlike peptide-1 has a physiological role in the control of postprandial glucose in humans: studies with the antagonist exendin 9-39. Diabetes 48:86-93

11. Mentlein R, Gallwitz B, Schmidt WE (1993) Dipeptidylpeptidase IV hydrolyses gastric inhibitory polypeptide, glucagon-like peptide-1-(7-36) amide, peptide histidine methionine, and is responsible for their degradation in human serum. Eur $\mathrm{J}$ Biochem 214:829-835

12. Berghofer P, Peterson RG, Schneider K, Fehmann HC, Goke B (1997) Incretin hormone expression in the gut of diabetic mice and rats. Metabolism 46:261-267

13. Vilsboll T, Agerso H, Krarup T, Holst JJ (2003) Similar elimination rates of glucagon-like peptide-1 in obese type 2 diabetic patients and healthy subjects. J Clin Endocrinol Metab 88:220-224

14. Meneilly GS, Demuth HU, McIntosh CH, Pederson RA (2000) Effect of ageing and diabetes on glucose-dependent insulinotropic polypeptide and dipeptidyl peptidase IV responses to oral glucose. Diabet Med 17:346-350

15. Pala L, Mannucci E, Pezzatini A et al (2003) Dipeptidyl peptidase-IV expression and activity in human glomerular endothelial cells. Biochem Biophys Res Commun 310:28-31

16. Mannucci E, Ognibene A, Sposato I et al (2003) Fasting plasma glucose and glycated haemoglobin in the screening of diabetes and impaired glucose tolerance. Acta Diabetol 40:181-186

17. Durinx C, Neels H, Van der Auwera JC, Naelaerts K, Scharpe S, De Meester I (2001) Reference values for plasma dipeptidylpeptidase IV activity and their association with other laboratory parameters. Clin Chem Lab Med 39:155-158

18. Augustyns K, Bal G, Thonus G et al (1999) The unique properties of dipeptidyl-peptidase IV (DPP IV/CD 26) and the therapeutic potential of DPP-IV inhibitors. Curr Med Chem 6:311-327

19. Mannucci E, Ognibene A, Cremasco F et al (2001) Effects of metformin on glucagon-like peptide-1 (GLP-1) and leptin levels in obese non-diabetic subjects. Diabetes Care 24:489-494

20. Deacon CF, Nauck MA, Meier J, Hucking K, Holst JJ (2000) Degradation of endogenous and exogenous gastric inhibitory polypeptide in healthy and type 2 diabetic subjects as revealed using a new assay for the intact peptide. J Clin Endocrinol Metab 85:3575-3581

21. Rosenblum JF, Kozarich JW (2003) Prolyl peptidases: a serine protease subfamily with high potential for drug discovery. Curr Opin Chem Biol 7:496-504

22. Green BD, Mooney MH, Gault VA, Irwin N, Bailey CJ, Harriott P, Flatt PR, O'Harte FP (2004) Lys9 for Glu9 substitution in glucagon-like peptide-1(7-36)amide confers dipeptidylpeptidase-IV resistance with cellular and metabolic actions similar to those of established antagonists glucagon-like peptide-1(9-36)amide and exendin(9-39). Metabolism 53:252-259

23. Wettergren A, Wojdemann M, Holst JJ (1998) The inhibitory effect of glucagon-like peptide-1 (7-36)amide on antral motility is antagonized by its N-terminally truncated primary metabolite GLP-1 (9-36)amide. Peptides 19:877-892 